\title{
Assessment of Crack Growth in a Space Shuttle Main Engine First-Stage, High-Pressure Fuel Turbopump Blade
}

\author{
Ali Abdul-Aziz \\ Sverdrup Technology Inc. \\ Lewis Research Center Group \\ Brook Park, Ohio
}

March 1993

Prepared for

Lewis Research Center

Under Contract NAS3-25266

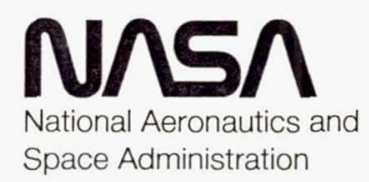




\title{
ASSESSMENT OF CRACK GROWTH IN A SPACE SHUTTLE MAIN ENGINE FIRST-STAGE,
}

\section{HIGH-PRESSURE FUEL TURBOPUMP BLADE}

\author{
Ali Abdul-Aziz \\ Sverdrup Technology, Inc. \\ Lewis Research Center Group \\ Brook Park, Ohio 44142
}

\section{SUMMARY}

A two-dimensional finite element fracture mechanics analysis of a space shuttle main engine (SSME) turbine blade firtree was performed using the MARC finite element code. The analysis was conducted under combined effects of thermal and mechanical loads at steady-state conditions. Data from a typical engine stand cycle of the SSME engine were used to run a heat transfer analysis and, subsequently, a thermal structural fracture mechanics analysis. Temperature and stress contours for the firtree under these operating conditions were generated. High stresses were found at the firtree lobes where crack initiation was triggered. A life assessment of the firtree was done by assuming an initial and a final crack size.

\section{INTRODUCTION}

The space shuttle main engine (SSME) is a high-performance liquid propellant rocket engine producing $2277 \mathrm{kN}$ of thrust at full power level. It uses four turbopumps, two high pressure and two low pressure. The two high-pressure pumps are driven by gas turbines powered by hydrogen-rich steam provided by individual preburners. The high operating pressures in these turbines, together with the extreme temperature transients, particularly during startup and cutoff, and the potentially degrading hydrogen environment, have led to problems with cracking of the turbine blades. These blades are known to undergo various failure modes and exhibit different damage mechanisms. However, the maximum temperature experienced by the first-stage, high-pressure fuel turbopump (HPFTP) blade, the focus of attention in this work, exceeds $1000{ }^{\circ} \mathrm{C}$ during startup conditions. As a result of these severe operating conditions, several cracks were cited at different locations in the turbopump blades, specifically at the shank and firtree (ref. 1). The first shank crack observed was of substantial size and depth and prompted a detailed periodical visual inspection program that is continuing to the present. The first cracks observed originated in the contact area of the firtree lobe at the downstream, pressure side of the blade. Immediately following these initial discoveries, a detailed program to understand the nature of these cracks was initiated (ref. 1). It was found that these cracks were initiated at $0.127 \mathrm{~mm}$ to $0.508 \mathrm{~mm}$ from the trailing edge and some traveled into the blade as much as $10.16 \mathrm{~mm}$. Also, metallographic analysis of the fracture surfaces indicated that these cracks initiated and propagated during engine cycles in low-cycle fatigue. A thorough fracture mechanics analysis would be of potential benefit to assess the extent of damage and determine the life of the blade under these conditions.

Therefore, this report investigates the aforementioned cracking problems in the blade firtree region through a two-dimensional elastic-plastic fracture mechanics analysis. The MARC finite element code (ref. 2) is used to carry out these calculations. 


\section{PROBLEM DESCRIPTION}

The SSME blade was chosen for this study because of a history of crack initiations caused by the large thermal gradients during startup and cutoff transients and post-preburner ignition. The solid blade (fig. 1) is cast of a directionally solidified MAR-M246+(Hf) nickel base superalloy. It has a length of $4.19 \mathrm{~cm}$, with an airfoil span length of $2.2 \mathrm{~cm}$ and a span-to-chord width aspect ratio of approximately unity. Temperature-dependent properties for this alloy were provided by Rockwell International Corporation (ref. 3). A finite element model consisting of disk attachments and a firtree was generated by using the PATRAN code (ref. 4). Because of the symmetry of the configuration, only half of the blade/disk was modeled (fig. 2).

In this analysis, however, only the firtree model was considered. The disk was excluded from the analysis to assess its significance, to simplify the problem, and to save on computation and turnaround time. The finite element model, shown in figure 3, consists of 1391 eight-noded plane strain elements and 4462 nodes.

\section{ANALYTICAL PROCEDURE}

Although the lack of accurate temperature, pressure, and heat flux data below the platform severely limits evaluation of these potential low-cycle fatigue drivers, an analysis was carried out on the basis of what is available. The subsequent paragraphs describe the steps covered during this analysis.

\section{Heat Transfer Analysis}

The thermal environment beneath the platform region is not well defined, making it difficult to assess an accurate temperature field in that area. However, in this analysis, thermal load was needed as an input for the subsequent thermal structural analysis. Thus, a heat transfer analysis was performed to predict the temperatures experienced by the firtree. Furthermore, the heat transfer situation at this particular section of the blade (platform-shank-firtree-disk interfaces) is a combination of both convection and conduction phenomena. Since the disk attachments were excluded from the analysis, the conduction effects at the disk-firtree contact interfaces were simulated by boundary conditions. This arrangement was implemented by adjusting the gas temperature to account for the amount of heat generated through conduction by the disk attachments, as if they were actually included in the model. Results obtained from the analysis were very consistent and comparable with previously obtained unpublished results of analysis done with the disk attachments included.

The top of the firtree was fixed by a temperature that simulated the existence of the shank and platform regions, and the line of symmetry was insulated. The elements at the lobe with disk interface were assigned film coefficients and the corresponding sink temperature according to the thermal boundary conditions. The analysis was conducted at steady-state conditions using existing data obtained from reference 1 for the film coefficients and for the gas temperature. Variations of thermal properties with temperature and other related boundary conditions were introduced through the analysis via the MARC code data input options. Heat transfer data used for the analysis at the firtree are shown in figure 4. 


\section{Stress Intensity Factor}

The concern in this analysis is to determine conditions under which crack propagation occurs. This is done by calculating the elastic-plastic energy release rate, which is confined to a single parameter: the strength of the singularity in the elastic-plastic stress field at the crack tip. This stress intensity factor is usually denoted by the symbol $\mathrm{K}$. The magnitude of $\mathrm{K}$ depends on the crack length, the distribution and intensity of applied loads, and the geometry of the structure. Crack propagation will occur when any combination of these factors causes $\mathrm{K}$ to be equal to or greater than the experimentally determined material threshold value (ref. 5). The equation that relates $\mathrm{K}$ to the energy release rate is given by the following relation (ref. 2):

$$
K=\sqrt{E \frac{d W}{d A}}
$$

where $\mathrm{K}$ is the stress intensity factor in $\mathrm{MPa} \cdot(\mathrm{m})^{1 / 2}, \mathrm{E}$ is the modulus in $\mathrm{MPa}, \mathrm{W}$ is the strain energy in $\mathrm{Kgf} \cdot \mathrm{m}$, and $\mathrm{dW} / \mathrm{dA}$ is the energy release rate during a small crack extension $\mathrm{dA}$ where $\mathrm{A}=\mathrm{a} \cdot \mathrm{b}$ and $\mathrm{a}$ and $\mathrm{b}$ are the crack length and the crack width, respectively, in meters. Once the functional forms of $\mathrm{K}$ have been determined, the state of the stress and displacement near the crack tip region of structure can be determined. However, because of the large nonlinearity at high temperature, a nonlinear fracture parameter is needed. Thus, the J-Integral offers a good approach that is readily available within the MARC code to have a single parameter to relate to the singularity at the crack tip.

\section{J-Integral Calculations}

The J-Integral evaluation was determined by invoking the J-Integral parameter option in the MARC code. This resulted in calculation of the change in strain energy due to nodal movement near the crack tip. The plastic strains were included in the definition of the strain energy change for the elastic-plastic analysis. Among the options available in the MARC code is the extended J-Integral option of Kishimoto and Delorenzi; it was chosen for the analysis since it accounts for various effects such as thermal loading, inertia forces, and plastic deformations. Evaluation of the J-Integral in MARC is based on node movement and numerical differentiation to obtain the change in the potential energy as a function of nodal positions (ref. 6). It is assumed that the loads are not changed by node movements so that the only concern is the energy change, which is given by

$$
\mathrm{E}=\sum_{\text {elements }} \int_{\mathrm{V}} \mathrm{W}^{\mathrm{e}}(\varepsilon) \mathrm{dV}
$$

where the $\sum$ represents an appropriate sum over nodes associated with the element whose volume is represented in the integral and $W\left(\varepsilon^{\mathrm{e}}\right)$ is the strain energy density. This quantity is evaluated by numerical integration at each increment for each prescribed nodal movement to evaluate the derivative of the strain energy with respect to the crack length at the end of each increment. More details pertaining to the formulation of the J-Integral may be found in the MARC theoretical manual (ref. 2). 


\section{Quarter Point Elements Application}

To overcome the difficulty that is usually encountered in the finite element fracture mechanics representation of the solution near the crack tip, the mesh must be modeled so that the singularity is approximated with sufficient accuracy. Many methods have been established to arrive at such an approximation; however, the most commonly used method uses a degenerate form of the standard eight-node quadrilateral element. This method is usually referred to as the " $1 / 4$ " point node technique (ref. 7 ). This is also the preferred technique for analyses with the MARC code. It is applied by using eight-node quadrilateral elements. The nodes on the midsides adjacent to the crack tip are moved to one quarter of the edge length, and the edge opposite the crack is kept straight. When these steps are followed, a singularity in the stress field exists in all directions going outward radially from the crack tip.

\section{Boundary Conditions}

In this analysis, getting the boundary conditions to meet some of the specific requirements needed for the analysis was quite complex and tedious. Since only the blade firtree was considered for the analysis, the airfoil and shank region had to be compensated for by imposing additional load on the firtree. This was determined by calculating the force due to rotational speed by using the equation for a rotating disk with uniform thickness. With knowledge of the mass per unit volume of the blade, the angular velocity, and the disk radius, the force imposed can easily be determined. This is shown by the following equation:

$$
\mathrm{F}_{\mathrm{r}}=\rho \omega^{2} \mathrm{r}
$$

where $\rho$ is the mass density, $\omega$ is the angular velocity, and $\mathrm{r}$ is the disk radius.

Similarly, the radial displacements of the firtree lobes as a result of rotational speed had to be calculated. The equation of rotating disks with uniform thickness for calculating radial displacements was used, and the values calculated were incorporated into the analysis. The mechanical boundary conditions were applied in a way that the nodal points at the center of the firtree by the line of symmetry were fixed along the $\mathrm{Y}$-axis and the nodal points along the lobes were allowed to move by the calculated displacement in the $\mathrm{X}$-axis direction of a coordinate system that was established normal to the lobe surface. Thus the total load being applied consisted of a combination of both mechanical and thermal loads.

\section{Life Prediction Computation}

The estimation of life based on the data obtained from this analysis was handled by using the Paris (ref. 8) relation that ties the number of life cycles to the crack length and the stress intensity factor. This relation is described by the following equation:

$$
\mathrm{dN}=\frac{\mathrm{da}}{\mathrm{c}(\Delta K)^{\mathrm{n}}}
$$

where $\mathrm{N}$ is the number of life cycles, da is the incremental crack length, $\Delta \mathrm{K}$ is the stress intensity factor range $\left(\mathrm{K}_{\max }-\mathrm{K}_{\min }\right)$, and $\mathrm{c}$ and $\mathrm{n}$ are material constants determined from experimental data. The life 
cycle in this analysis is defined as a combination of the mechanical loading and the steady-state temperature, with the mechanical loading changing as the rotational speed changed from 0 to $36000 \mathrm{rpm}$.

The high stresses from the elastic-plastic analysis were observed at all four lobes along the contact surface with the disk. However, the area with the largest plastic zone was confined to the fourth lobe where crack initiation was more likely to take place. Hence, the crack analysis was initiated at the nodal point of the element with the highest stresses at the fourth lobe and was advanced downward toward the middle of the firtree. Figure 5 shows the crack advancement as a function of distance. An initial crack length $\left(\mathrm{a}_{0}\right)$ can be assumed to be $0.127 \mathrm{~mm}$, which corresponds to an acceptable microporosity size suggested by Lee (ref. 9). However, computations were made with a crack length of $0.06185 \mathrm{~mm}$, and the life calculations are only valid for a crack size range of 0.127 to $0.381 \mathrm{~mm}$. The J-Integral analysis resulted in determining the energy release rate, and the stress intensity factor was calculated for each time the crack advanced using equation (1). The crack site temperature was approximately $482^{\circ} \mathrm{C}$.

The fatigue crack growth data required to perform the life analysis was collected from available unpublished data. Based on the data, it was found that the values of constants $\mathrm{n}$ and $\mathrm{c}$ needed in equation (4) are in the range of 2 to 3 for $\mathrm{n}$ and about $1.2 \times 10^{-9}$ to $2.0 \times 10^{-9}$ for $\mathrm{c}$. They represent a certain range of operating temperatures and a specific environment (air or hydrogen). However, for the purpose of this study and for the sake of calculating the life, values of 2.4 and $1.90 \times 10^{-9}$ were chosen for $\mathrm{n}$ and $\mathrm{c}$ as intermediate numbers. Those values were the best approximation and the most suitable for this material to perform the life calculations under the current operating conditions.

\section{RESULTS AND DISCUSSION}

Results and findings from this analysis are discussed and presented in this section. Contour plots of temperature and stresses at different conditions are shown in figures 6 to 13 .

Figure 6 represents the steady-state temperature distribution of the firtree. It averaged about $482^{\circ} \mathrm{C}$ at the shank-firtree interface, and it uniformly decreased toward the bottom lobes as expected, since the cooling effects are much higher in that region than in the top portion of the firtree. Also, the temperature gradient in the radial direction is quite steep considering the physical size of the firtree. This is a major factor in inducing high thermal stresses in the region. Full power level conditions that covered the steady state portion of the mission cycle were used to run these calculations.

The elastic-plastic analysis of the firtree covered the effects of both centrifugal and thermal loadings. The mechanical and thermal properties were supplied to the code as a function of temperature by defining a yield criterion and a strain hardening law. The calculations were based on incremental plasticity theory using the Von Mises yield criterion, the normality rule, and a kinematic hardening model. The residual load corrections were applied to ensure that equilibrium was maintained at the start of each new increment. The mechanical load was subdivided into 20 incremental loads in order to ensure convergence and to keep within the tolerance chosen. Each run of the analysis required a total control processing unit (CPU) time of about $5420 \mathrm{sec}$ on the CRAY-YMP computer in addition to 1.6 million words of memory.

Figure 7 shows the radial stresses or stresses along the span direction of the blade as a result of the elastic-plastic finite element analysis. As expected because of the high centrifugal and thermal loads applied, the highest stresses were located at the lobes' interface with the disk. The stress level averaged from about $924 \mathrm{MPa}$ to about $69 \mathrm{MPa}$ near the base. Figures 8 and 9 illustrate the stresses of the fracture mechanics analysis with the crack advancing at two stages. Figure 5 shows the corresponding two points selected to show the advancement of the crack at nodal points 3 and 5, which refer to stages 1 and 2 . The 
first stage is represented in figure 8 , which shows the size of the plastic zone encountered at the crack site as the crack advanced from nodal point 1 to nodal point 3 (fig. 5). The second stage is shown in figure $9(\mathrm{a})$ with the crack advancing more towards the inner region of the firtree as the crack moved from nodal point 1 to nodal point 5 (fig. 5). Figure 9(b) duplicates figure 9 (a) with a closer view of the crack at nodal point 5 . These results show that the plastic region at the crack tip grows larger as the crack advances. This is an indication of high thermal stresses due to the thermal gradient experienced during engine operation. In addition, the forces caused by the fluid due to rotor-firtree interaction are another cause for these high stresses. The level of stresses experienced as the crack advanced was about $1000 \mathrm{MPa}$ for all cases, with a slight variation of approximately $\pm 34.5 \mathrm{MPa}$ from one case to another.

Figure 10 shows the stress intensity factor as a function of engine speed. Initially, as the engine speed increased, the value of $\mathrm{K}$ increased accordingly. When the engine speed reached about $22000 \mathrm{rpm}$, though, $\mathrm{K}$ maintained an average value of about $15.38 \mathrm{MPa}(\mathrm{m})^{1 / 2}$. This also conveyed the effects of engine speed on the variations of the energy rate as the crack length and engine speed changed. Figure 11 shows the stress intensity factor as a function of crack length. As the crack advances, the stress intensity factor increases, reflecting the level of plasticity invoked as a result of crack deepening.

Figure 12 represents the variation of the radial stresses normalized by the yield strength of the material as a function of crack length for two different crack advancements. It is well noted from this plot that the plastic zone grew initially and reached a stabilizing point thereafter. These stresses are the centroidal values of the radial stresses, and were transformed via equation (5) to represent the normal stresses to the crack length with $\theta$ being the angle between the crack length and the radial axis:

$$
\sigma_{\mathrm{x}^{\prime}}=\sigma_{\mathrm{x}} \cos ^{2} \theta+\sigma_{\mathrm{y}} \sin ^{2} \theta+2 \tau_{\mathrm{xy}} \sin \theta \cos \theta
$$

Figure 13 illustrates the cyclic life and its relation to the crack length. The figure shows that for a crack length of $0.381 \mathrm{~mm}$, the estimated life is about 12000 cycles. However, the life determination is highly dependent on the values of constants $n$ and $c$, which means that the calculations presented here depend on the accuracy of the choices for $\mathrm{n}$ and $\mathrm{c}$. In this analysis, the values used for $\mathrm{n}$ and $\mathrm{c}$ were best approximations for this material under the conditions considered; however, one other thing must be kept in mind, that these results are dependent on the boundary conditions used and on the fact that the combined firtree-disk structure was not modeled.

\section{CONCLUSIONS}

A two-dimensional, elastic-plastic finite element fracture mechanics analysis was performed on the firtree of the first-stage, high-pressure fuel turbopump blade (HPFTP) of the space shuttle main engine (SSME). The analysis was carried out under combined thermal and mechanical loadings. Results showed that the four lobes of the firtree experience high stresses which can lead to cracking. The firtree was shown to have a life in the tens of thousands of cycles before failure. However, the following points may have influenced the results:

1. The lack of accurate temperature, pressure, and heat flux data below the platform severely limits evaluation of these potential low-cycle fatigue drivers, which, in return, may have some effects on the accuracy of the results presented.

2. More engine testing is needed to provide a better understanding of whether the transient or mainstage thermal influence is dominant. 
3. A future analysis of the complete structure which covers the whole blade with the disk attachments would be more helpful in providing more accurate assessments of the damage and failure modes experienced.

4. Although the thermally induced stresses are obviously sufficient to cause cracking of the DS MAR-M 246+(Hf) in the hydrogen-rich environment, the limited depth of these cracks implies a local surface effect that decreases rapidly. However, these cracks may ultimately grow because of high cycle fatigue mechanisms produced by the centrifugal and pressure loadings.

\section{REFERENCES}

1. SSME Turbine Blade Analysis Team Report. Rockwell International, Canoga Park, CA, NASA Contract NAS8-27980, Dec. 1986.

2. MARC Finite Element Code: User Information Manual. Vols. A and C. Marc Research Analysis Corporation, Palo Alto, CA, 1990.

3. Materials Properties Manual. Fourth ed. Rockwell International Corporation, Rocketdyne Division, Canoga Park, CA, 1987.

4. PATRAN Plus Graphic and Finite Element Package. Vols. I and II. PDA Engineering, Costa Mesa, CA, 1989.

5. Rice, J.R.; and Tracy, D.M.: Computational Fracture Mechanics. Proceedings of the Symposium on Numerical and Computer Methods in Structural Mechanics, S.J. Fenves et al., eds., Academic Press, New York, 1973, pp. 585-623.

6. Nagtegaal, J.C.; and de Jong, J.E.: Some Computational Aspects of Elastic-Plastic Large Strain Analysis. Int. J. Numer. Methods Eng., vol. 17, Jan. 1981, pp. 15-41.

7. Barsoum, R.S.: On the Use of Isoparametric Finite Elements in Linear Fracture Mechanics. Int. J. Numer. Methods Eng., vol. 10, no. 1, 1976, pp. 25-37.

8. Paris, P.C.; and Erdogan, F.: A Critical Analysis of Crack Propagation Laws. JBAE-A, J. Basic Eng., vol. 85, Dec. 1963, pp. 528-534.

9. Lee, H.: Space Shuttle Main Engine High Pressure Fuel Turbopump Turbine Blade Cracking. NASA TM-100327, 1988. 


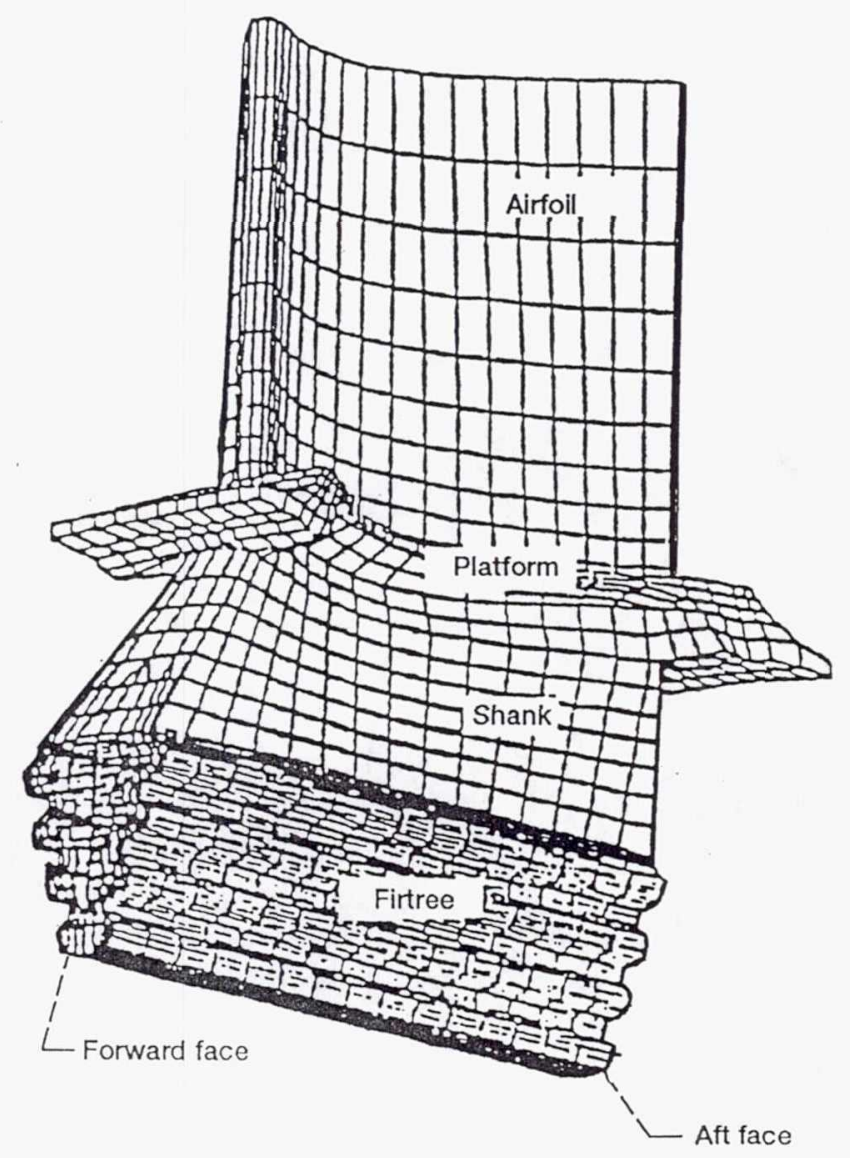

Figure 1.-First-stage space shuttle main engine turbine blade.

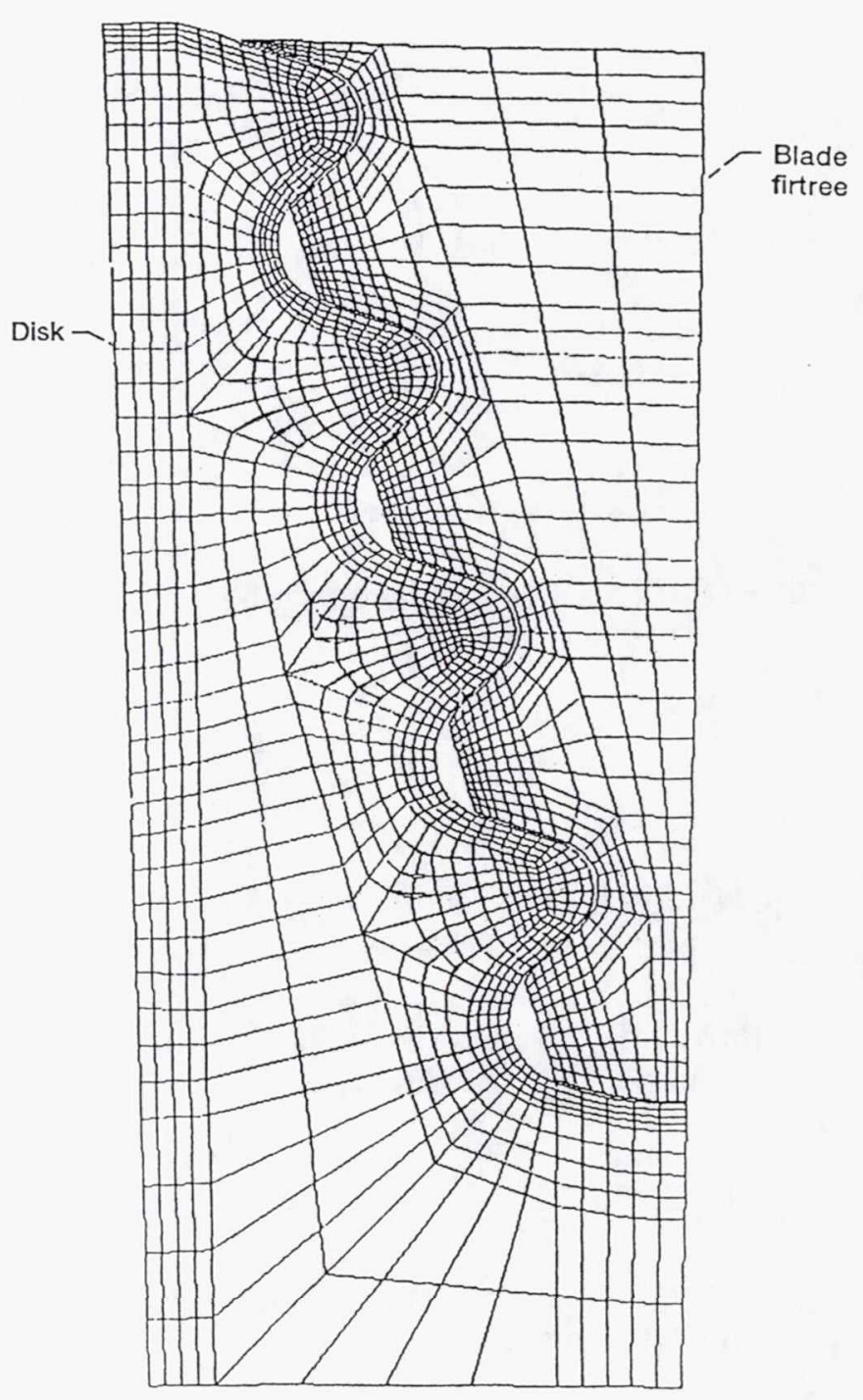

Figure 2.-Finite element model of blade and disk attachments. 

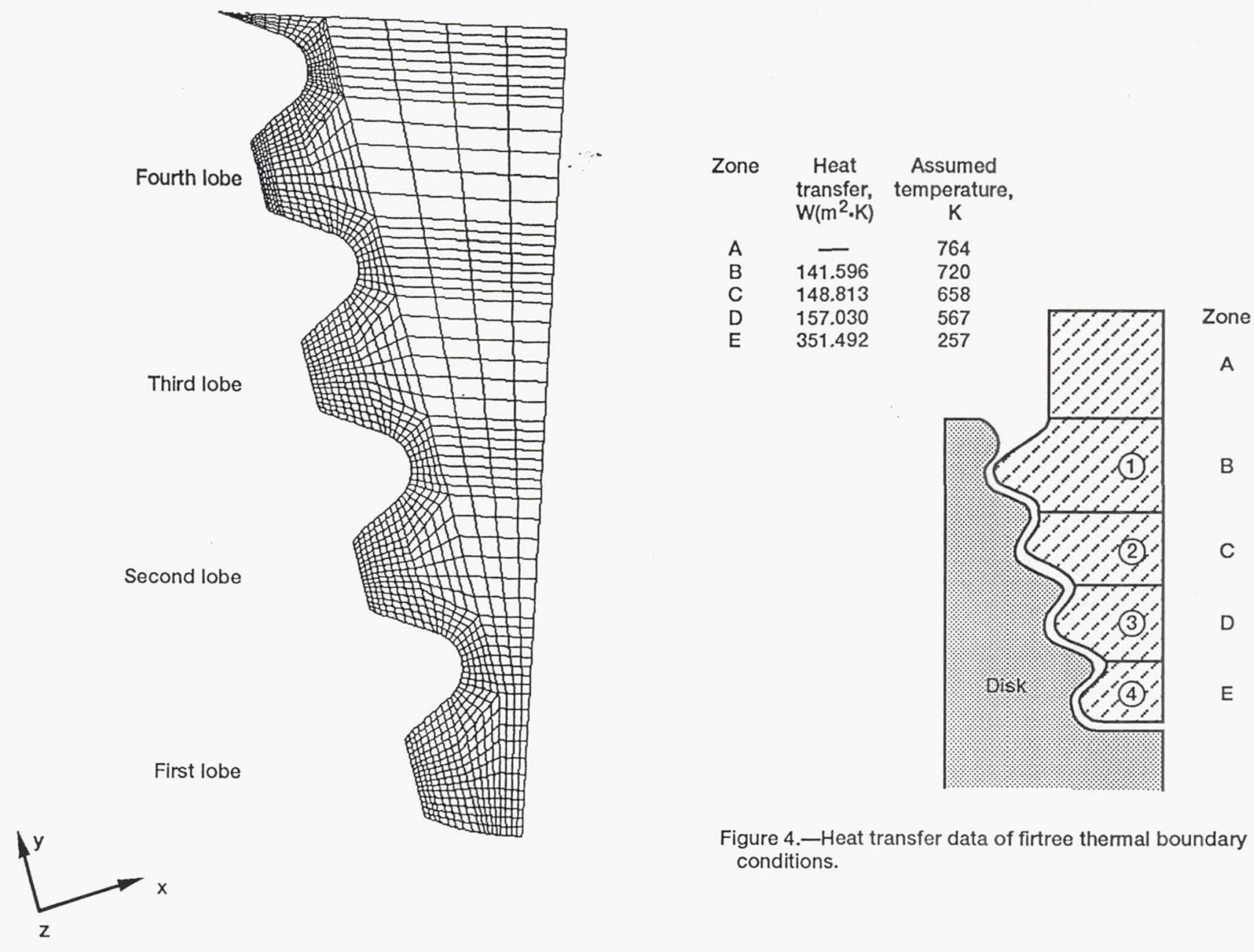

Figure 4.- Heat transfer data of firtree thermal boundary conditions.

Figure 3.-Firtree finite element model (1390 eight-noded quadilateral plain strain elements, 4462 nodes). 

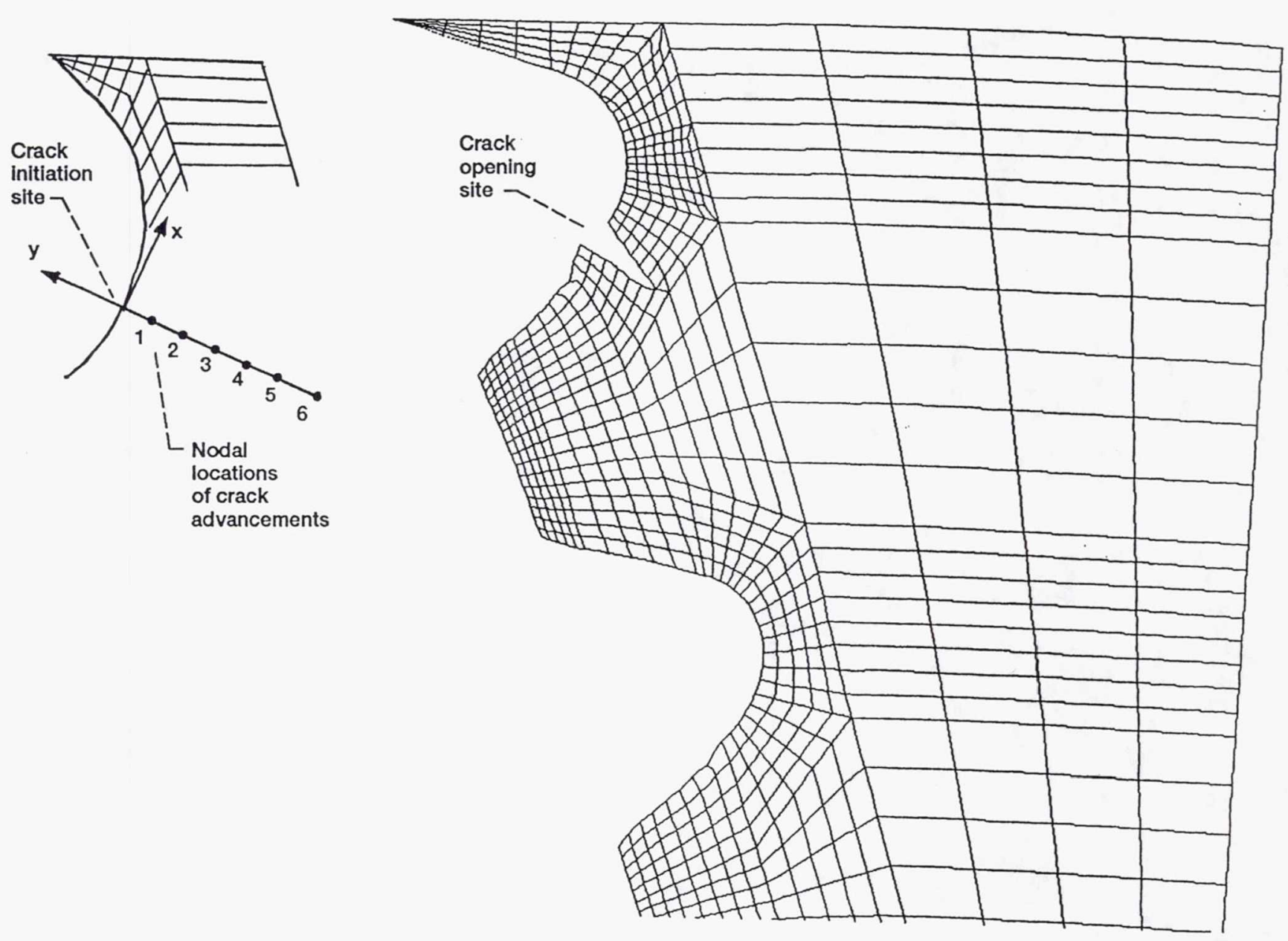

Figure 5.-Crack opening site. 


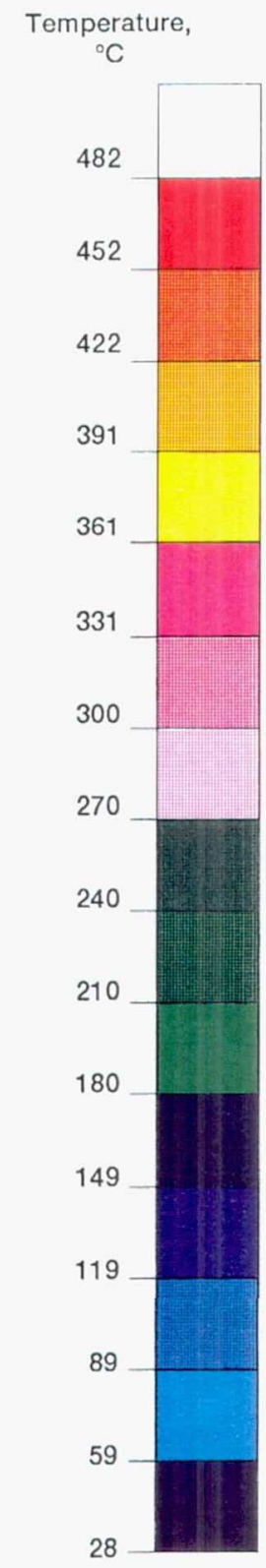

Figure 6.-Steady-state temperature distribution. 
Page intentionally left blank 


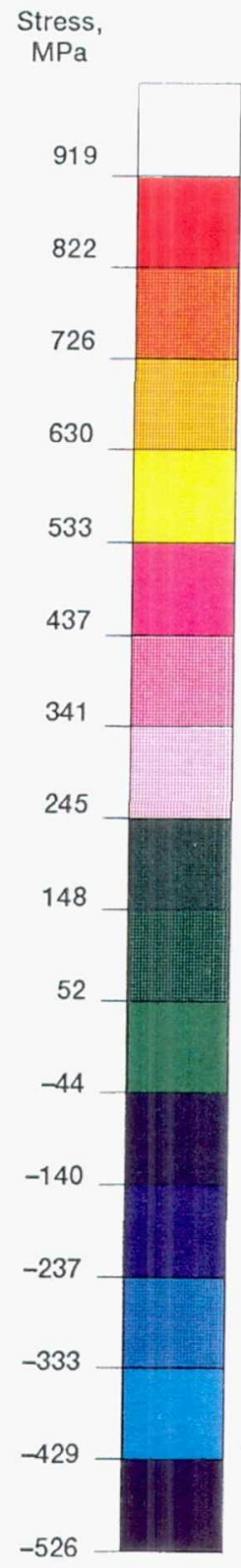

Figure 7.-Radial stresses as result of elastic-plastic analysis. 
Page intentionally left blank 

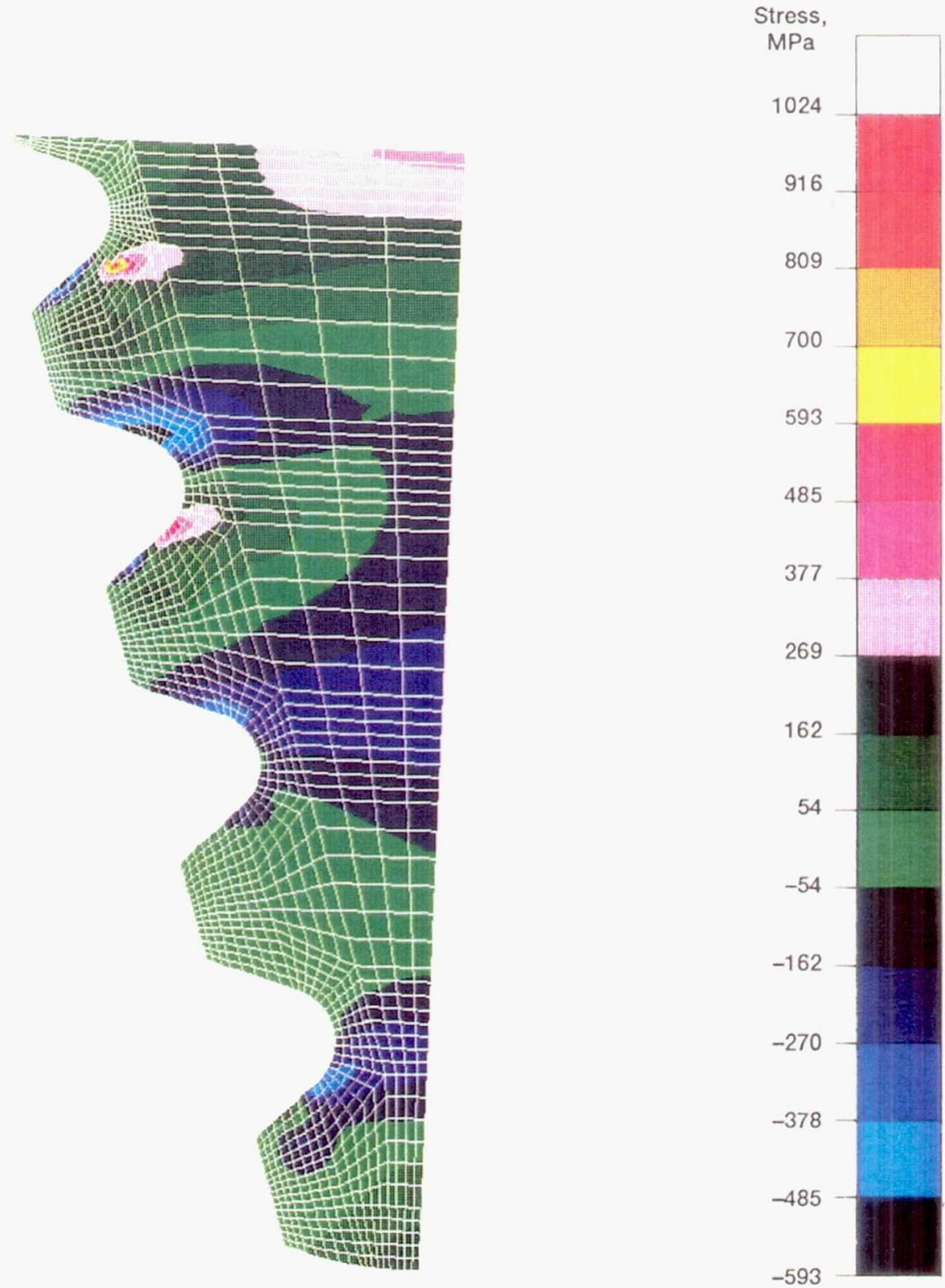

Figure 8.-Radial stresses as crack advances at nodal point 3 (see fig. 5). 
Page intentionally left blank 

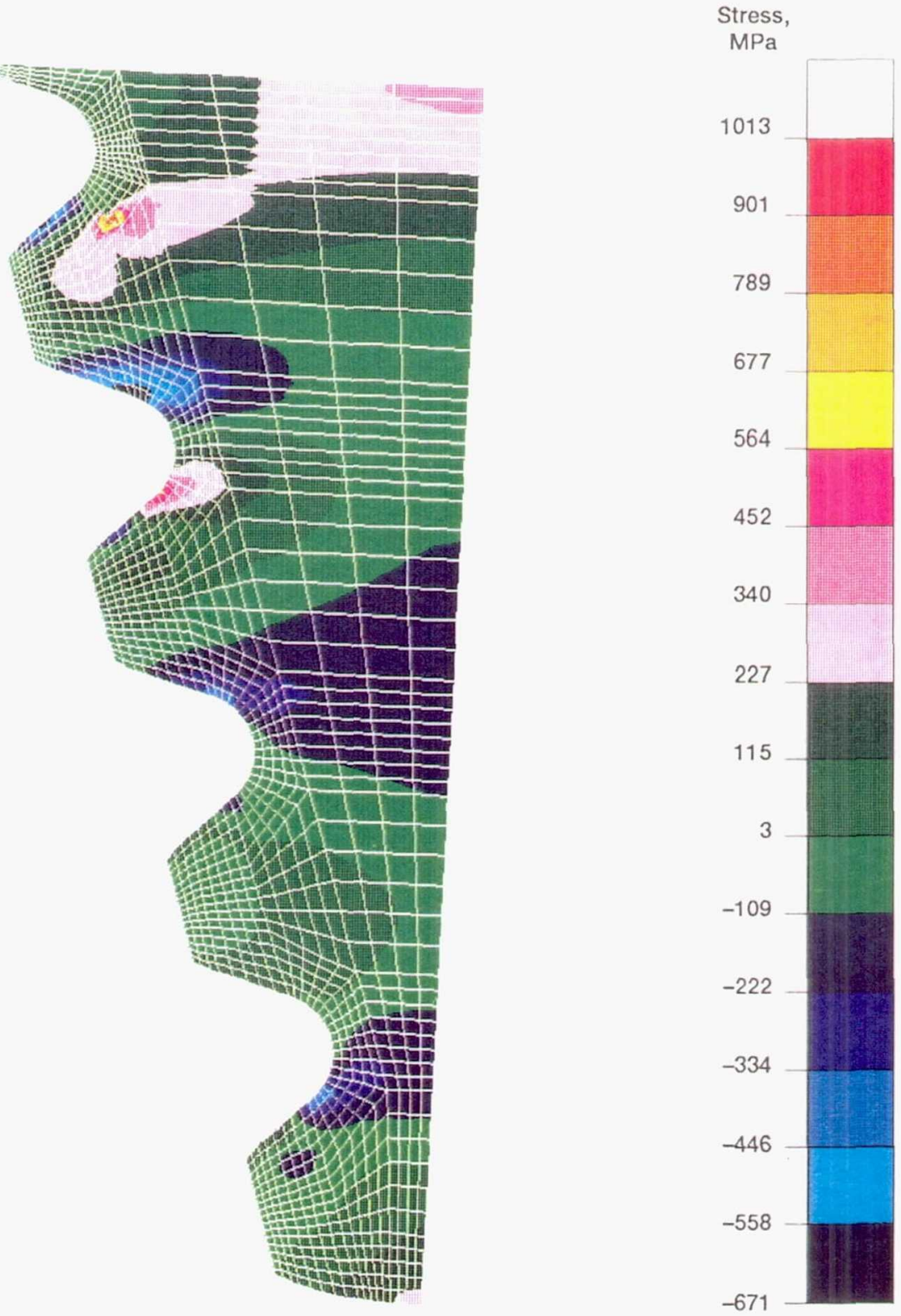

(a) Full view.

Figure 9.-Radial stresses as crack advances at nodal point 5 (see fig. 5). 
Page intentionally left blank 


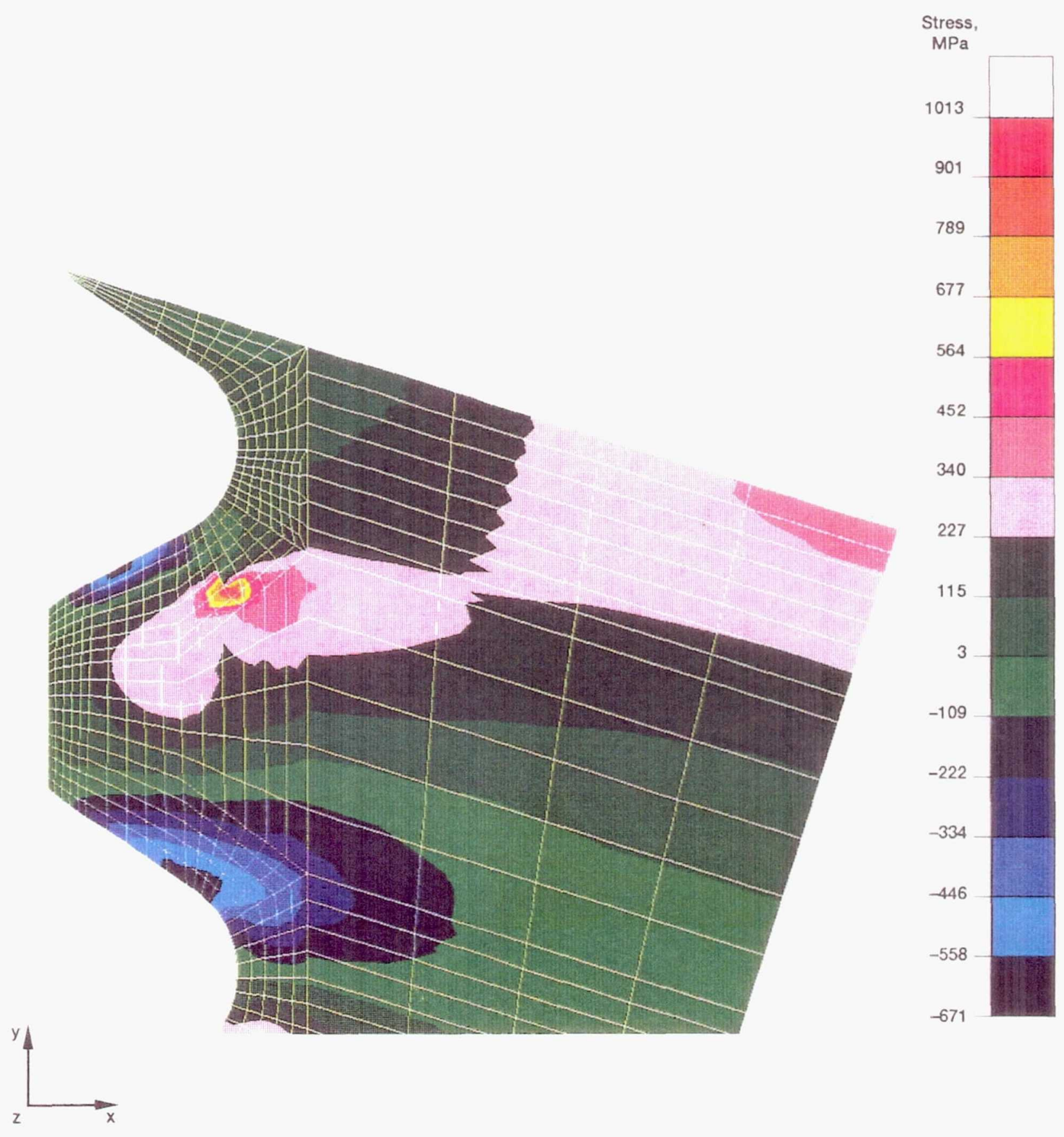

(b) Closer view.

Figure 9.-Concluded. 
Page intentionally left blank 


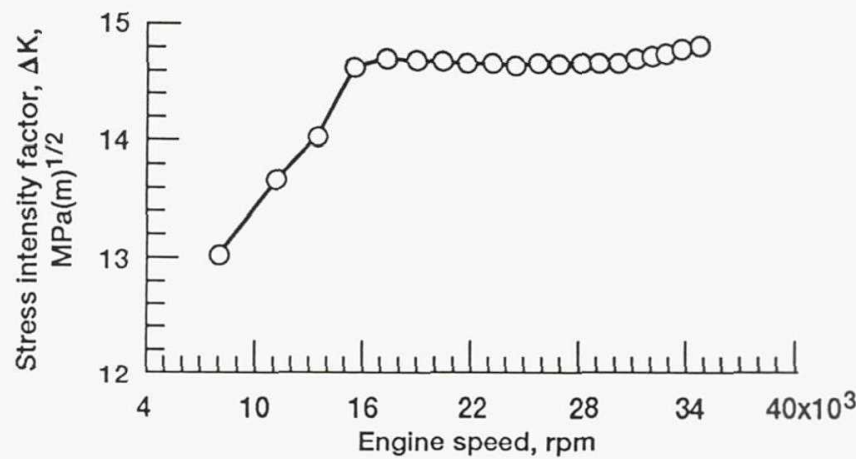

Figure 10.-Stress intensity factor as function of engine speed.

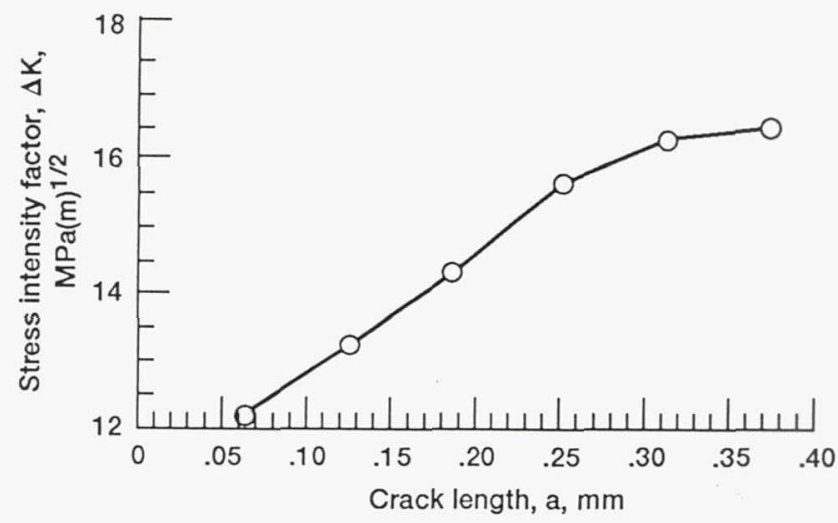

Figure 11.-Stress intensity as function of crack length. 


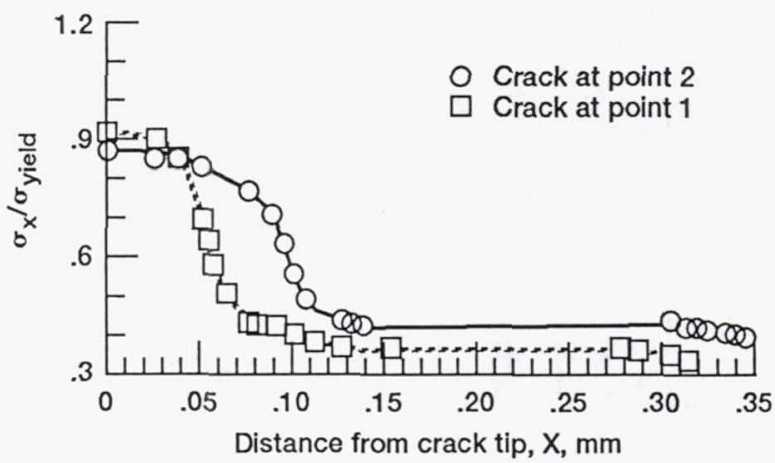

Figure 12.-Normalized radial stress by yield strength as function of distance from crack tip.

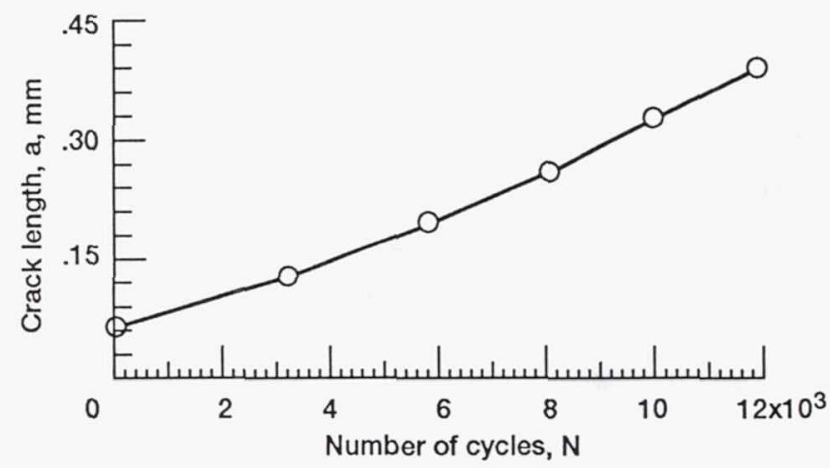

Figure 13.-Expected life as function of crack length. 
Public reporting burden for this collection of information is estimated to average 1 hour per response, including the time for reviewing instructions, searching existing data sources, gathering and maintaining the data needed, and completing and reviewing the collection of information. Send comments regarding this burden estimate or any other aspect of this Davis Highway, Suite 1204, Arlington, VA 22202-4302, and to the Office of Management and Budget, Paperwork Reduction Project (0704-0188), Washington, DC 20503.

\begin{tabular}{|c|c|c|}
\hline 1. AGENCY USE ONLY (Leave blank) & $\begin{array}{l}\text { 2. REPORT DATE } \\
\text { March } 1993\end{array}$ & $\begin{array}{l}\text { 3. REPORT TYPE AND DATES COVERED } \\
\text { Final Contractor Report }\end{array}$ \\
\hline
\end{tabular}

Assessment of Crack Growth in a Space Shuttle Main Engine First-Stage,

High-Pressure Fuel Turbopump Blade

WU-553-13-00

6. AUTHOR(S)

Ali Abdul-Aziz

7. PERFORMING ORGANIZATION NAME(S) AND ADDRESS(ES)

Sverdrup Technology, Inc.

8. PERFORMING ORGANIZATION

REPORT NUMBER

Lewis Research Center Group

2001 Aerospace Parkway

E-7396

Brook Park, Ohio 44142

9. SPONSORING/MONITORING AGENCY NAMES(S) AND ADDRESS(ES)

10. SPONSORING/MONITORING

National Aeronautics and Space Administration

Lewis Research Center

Cleveland, Ohio 44135-3191

NASA CR-190782

11. SUPPLEMENTARY NOTES

Project Manager, Mike McGaw, (216) 433-3308.

12a. DISTRIBUTION/AVAILABILITY STATEMENT

12b. DISTRIBUTION CODE

Unclassified - Unlimited

Subject Category 39

13. ABSTRACT (Maximum 200 words)

A two-dimensional finite element fracture mechanics analysis of a space shuttle main engine (SSME) turbine blade firtree was performed using the MARC finite element code. The analysis was conducted under combined effects of thermal and mechanical loads at steady-state conditions. Data from a typical engine stand cycle of the SSME engine were used to run a heat transfer analysis and, subsequently, a thermal structural fracture mechanics analysis. Temperature and stress contours for the firtree under these operating conditions were generated. High stresses were found at the firtree lobes where crack initiation was triggered. A life assessment of the firtree was done by assuming an initial and a final crack size.

\begin{tabular}{|c|c|c|}
\hline 14. SUBJECT TERMS \\
\hline $\begin{array}{c}\text { 17. SECURITY CLASSIFICATION } \\
\text { OF REPORT } \\
\text { Unclassified }\end{array}$ & $\begin{array}{c}\text { 18. SECURITY CLASSIFICATION } \\
\text { OF THIS PAGE } \\
\text { Unclassified }\end{array}$ & $\begin{array}{c}\text { 19. SECURITY CLASSIFICATION } \\
\text { OF ABSTRACT } \\
\text { Unclassified }\end{array}$ \\
\hline
\end{tabular}


National Aeronautics and Space Administration

Official Business

Penalty for Private Use $\$ 300$

\section{ADDRESS CORRECTION REQUESTED}

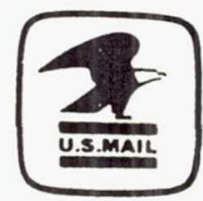

Postage and Fees Paid National Aeronautics and

Space Administration NASA 451 